\title{
Metformin and ageing: improving ageing outcomes beyond glycaemic control
}

\author{
Willy Marcos Valencia ${ }^{1,2} \cdot$ Ana Palacio ${ }^{1,2,3} \cdot$ Leonardo Tamariz $^{1,2,3} \cdot$ Hermes Florez $^{1,2,3}$
}

Received: 21 March 2017 / Accepted: 17 May 2017 /Published online: 2 August 2017

(C) US Government (outside the USA) 2017

\begin{abstract}
In a world where the population is ageing, there is growing interest and demand for research evaluating strategies that address the ageing process. After 60 years of successful use of metformin in our pharmaceutical armamentarium, we are learning that, beyond improving glycaemic control, metformin may have additional mechanisms and pathways of action that need further study. Although, metformin's effect on clinical ageing outcomes may still be considered speculative, the findings from studies into cellular and animal models and from observational and pilot human studies support the existence of beneficial effects on ageing. At present, progress for human research, using randomised clinical trials to evaluate metformin's clinical impact, has just started. Here, we present a review on the ageing process and the mechanisms involved, and the role that metformin may have to counter these. We go on to discuss the upcoming large randomised clinical trials that may provide insight on the use of metformin for ageing outcomes beyond glycaemic control.
\end{abstract}

Electronic supplementary material The online version of this article (doi:10.1007/s00125-017-4349-5) contains a slideset of the figures for download, which is available to authorised users.

Willy Marcos Valencia

willy.valencia-rodrigo@va.gov

1 Geriatric Research Education and Clinical Center (GRECC), Miami VA Healthcare System, 1201 N.W. 16th Street, (11 GRC) CLC 207 A2, Miami, FL 33125, USA

2 Department of Public Health Sciences, University of Miami Miller School of Medicine, Miami, FL, USA

3 Department of Medicine, University of Miami Miller School of Medicine, Miami, FL, USA
Keywords Ageing · Mechanisms of ageing · Metformin · Older adults $\cdot$ Review

$\begin{array}{ll}\begin{array}{l}\text { Abbreviations } \\ \text { CVD }\end{array} & \begin{array}{l}\text { Cardiovascular disease } \\ \text { DPPOS }\end{array} \\ \text { Diabetes Prevention Program Outcomes } \\ \text { Study } \\ \text { ePREDICE } & \begin{array}{l}\text { Early Prevention of Diabetes Complications } \\ \text { in Europe }\end{array} \\ \text { MCI } & \text { Mild cognitive impairment } \\ \text { mTOR } & \text { Mechanistic target of rapamycin } \\ \text { NCD } & \text { Noncommunicable diseases } \\ \text { ROS } & \text { Reactive oxygen species } \\ \text { TAME } & \text { Targeting Ageing with Metformin } \\ \text { VA-IMPACT } & \text { Veterans Affairs' Investigation of } \\ & \text { Metformin in Pre-Diabetes on } \\ & \text { Atherosclerotic Cardiovascular OuTcomes }\end{array}$

Introduction

The combination of a growing ageing population, longer life expectancy and greater prevalence of multiple chronic diseases is increasingly leading to social, economic and healthcare challenges for those in developed and developing countries. By 2050, the world's population aged 60 years and older is expected to reach 2 billion, increasing from 900 million in 2015. Of these, 125 million individuals are 80 years or older, a number that will rise to 434 million by 2050 , and $80 \%$ of them will live in low- and middle-income countries [1].

Ageing, insulin resistance and inflammation are associated with noncommunicable diseases (NCD), such as type 2 diabetes [2], cardiovascular diseases (CVD) [3], cancer [4], depression [5] and dementia [6], as well as frailty, a condition of 
increased vulnerability and poor health outcomes [7]. The prognosis and clinical outlook of an older adult with multimorbidity (a combination of several conditions within the medical domain) is further impaired by issues in the functional and psychological/mental domains (physical and cognitive dysfunction). Altogether, the ageing older person endures poor quality of life with increased vulnerability to losing independence, becoming hospitalised or dying. As our society is ageing, there is growing interest for research addressing interventions beyond healthy lifestyle to expand the number of functional years. Here, pharmacological therapy with safe and known agents, such as metformin, is of great interest.

Metformin has proven its efficacy for diabetes prevention and management. In the Diabetes Prevention Program (DPP), the efficacy of metformin in those aged 60 or older was not evident in the initial phase (using fasting and 2-h postchallenge glucose criteria) [8]. Nevertheless, long-term follow-up data, using $\mathrm{HbA}_{1 \mathrm{c}}$ level for diabetes diagnosis, showed that metformin was effective in all age categories, including in participants age 60 or older at baseline, in whom a $21 \%$ diabetes risk reduction was observed [9]. Ageing outcomes in the Diabetes Prevention Program Outcomes Study (DPPOS) included frailty and physical and cognitive function (ClinicalTrials.gov registration no. NCT00038727); preliminary analysis of these factors did not show any benefits of metformin or lifestyle interventions in this cohort (unpublished results, H. Florez). Notwithstanding, our knowledge of potential mechanisms leading to metformin benefits beyond glycaemic control is increasing, while efforts are being made to reduce the impact of conditions commonly associated with the ageing process. There are two large, randomised clinical trials (VA-IMPACT will start in 2017, and TAME has plans to start in 2018) aiming to evaluate these additional benefits of metformin for individuals without diabetes. Here, we outline the relevant pathways and mechanisms underlying the potential ability of metformin to reduce the burden of ageing and its related NCDs. We also discuss the available evidence on clinical benefits from observational studies, and details of the upcoming clinical trials that aim to shed light on the impact of metformin on ageing outcomes beyond glycaemic control.

\section{Ageing and its associated diseases}

There are different personal, cultural and societal perspectives on what constitutes 'ageing' and who are considered older adults. Using chronological age, the criterion for older adults in the USA is age $\geq 65$, whereas in Europe and other parts of the world, it is 60 years and older. Generally accepted biological definitions of ageing include "the declining ability to regenerate damaged tissue' [10] and 'a deterioration in the maintenance of homeostatic processes over time, leading to functional decline and increased risk for disease and death' [11]. These definitions, however, do not necessarily take into account the normal ageing process or even healthy ageing.

\section{Age-dependent and age-related diseases}

In order to understand the ageing process and how to intervene in it, it is important to highlight the difference between agedependent and age-related diseases. In age-dependent diseases, such as coronary artery disease, cerebrovascular disease, type 2 diabetes, osteoporosis and Alzheimer's Disease, the pathogenesis appears to involve basic ageing processes, chronic damage from inflammation [12] and dysregulated cellular metabolism [13]. Mortality and morbidity in these diseases increase exponentially with advanced age. In contrast, age-related diseases have a temporal relationship with the age of the host but are not necessarily related to the ageing process. These diseases occur at a specific age, but with a further increase in age, they either decline in frequency or increase at a less than exponential rate. Examples are gout, multiple sclerosis and many (but not all) cancers.

\section{Learning points}

Age-dependent diseases Pathogenesis involves mechanisms related to the ageing process, chronic inflammation and dysregulated cellular metabolism.

Age-related diseases Temporal relationship with age of host but are not necessarily associated with the ageing process.

Metformin might inhibit the ageing process Metformin reduces inflammation and ameliorates DNA and cellular damage. Data from definitive large randomised clinical trials in humans are lacking, but observational and pilot data show that metformin may improve clinical outcomes beyond diabetes, including cognition, depression and other ageing outcomes.

\section{Upcoming clinical trials of metformin}

1. VA-IMPACT: Participants with heart disease, without diabetes. Outcomes include time to death from any cause, myocardial infarction, stroke, hospitalisation for unstable angina, or symptom-driven coronary revascularisation.

2. TAME: Participants without diabetes. Outcomes include time to development of age-dependent diseases (e.g. cancer), CVD, dementia and type 2 diabetes.

3. ePREDICE: Participants with prediabetes. Outcomes include microvascular complications and cognitive function. 


\section{Mechanisms of ageing}

The process of ageing is complex and multifactorial. Nonetheless, physiological and evolutionary theories can be used to deduce the mechanisms of ageing [14]. Among these mechanisms of ageing, DNA damage receives the most attention, with hopes to identify pathways that can be contained or modified to halt or delay ageing itself. Endogenous sources for DNA damage include reactive oxygen species (ROS), alkylation and hydrolysis, whereas exogenous sources include chemicals and ultraviolet (UV) and other radiation [15]. Further, oxidative stress, a process where free radicals cause DNA damage, affecting protein translation, provides another mechanism of ageing via genetic damage [16]. Most of the data evidencing the process of ageing comes from animal experiments attempting to expand lifespan; blocking oxidative stress in older gerbils (aged 15-18 months) restored levels of function (assessed via the maze test for temporal and spatial memory) similar to that seen at younger stages of life, when the animals were aged 3 months [17].

The evolutionary theory of ageing assumes a linear increase in mutations over time and, whilst ageing and death are initially circumvented by cellular redundancy mechanisms [18], as mutations overwhelm the system, ineffective protein translation eventually occurs, resulting in ageing. From the cellular level, this leads to organ malfunction, causing decreased elasticity in skin, propensity to neoplasms, decreased strength and endurance, osteoporosis and many other conditions. In turn, this can lead to geriatric syndromes, in which frailty, delirium and falls are increased.

Table 1 highlights some of the physiological changes associated with ageing, their pathophysiological consequences and associated diseases $[14,19,20]$.

\section{The impact of metformin on mechanisms related to the ageing process}

Our current understanding of the mechanisms by which metformin improves glycaemic control includes the noncompetitive inhibition of the mitochondrial glycerophosphate dehydrogenase enzyme, which alters hepatocellular redox state, thus reducing the conversion of lactate and glycerol to glucose, decreasing hepatic gluconeogenesis [21]. As already mentioned, beyond the impact of metformin on glycaemic control, this drug is also proposed to alter mechanisms related to ageing (Fig. 1). For example, inflammatory markers, such as interleukins and TNF, can activate a variety of cellular processes that lead to cellular and tissue damage. IL-6 can induce fibroblast proliferation and collagen production, leading to cardiac remodelling. It can also promote myocyte hypertrophy, depressed contractility and apoptosis [22]. Metformin has been shown to alter inflammatory responses through suppression of NF-kB via AMP-activated protein kinase (AMPK)-dependent pathways [23-25]. In addition, metformin reduces the production of ROS through reverse electron flux [26] and via the mechanistic target of rapamycin (mTOR), leading to a reduction in superoxide, which may otherwise lead to DNA damage and mutations [27, 28].

High concentrations of ceramides in the skeletal muscle are also proposed to be involved in the ageing process. This can lead to reduced myoblast proliferation, aberrant cell cycle regulation and a senescent myoblast phenotype. Cell studies showed that treatment with metformin can limit the negative effects of ceramides, thus potentially preventing myoblast senescence [29]. This may potentially be helpful for the growing population of older adults with sarcopenic obesity, while possibly improving tissue health and function.

Similarly, other experimental models indicate that metformin may increase lifespan and delay the ageing process [30-32], as well as offer protection for specific tissues. A report indicated a potential cardioprotective role of metformin, since it stimulates ischaemia-induced revascularisation through an endothelial nitric oxide synthase-dependent pathway [33].

Other cell studies have shown that metformin may have a neuroprotective role, reducing neuronal injury and improving oxygen/glucose deprivation, resulting in better neuronal survival [34] and preventing etoposide-induced apoptosis in primary neurons [35]. In a mouse model of neuroblastoma, metformin normalised the diabetes-induced reduction of cell proliferation and neuroblast differentiation in the hippocampus [36]. Moreover, an in vitro model of insulin resistance using the Neuro-2a neuronal cell line demonstrated that metformin prevented the appearance of molecular and pathological characteristics associated with Alzheimer's Disease [37].

\section{Clinical impact of metformin beyond glycaemic control}

Research into metformin's clinical effects beyond glucose management originated from the observed reduction in cardiovascular risk in individuals with diabetes treated with metformin [38]. Since then, there is growing interest and reports suggesting clinical benefits beyond diabetes. Figure 2 summarises the potential clinical benefits of metformin in the ageing person.

\section{Cardiovascular health}

A recent cohort study of US older veterans with type 2 diabetes showed that metformin reduced CVD events among individuals with type 2 diabetes, according to the baseline risk [39]. The likelihood of CVD was reduced by $6 \%$ among otherwise healthy individuals, by $18 \%$ among those at risk of 


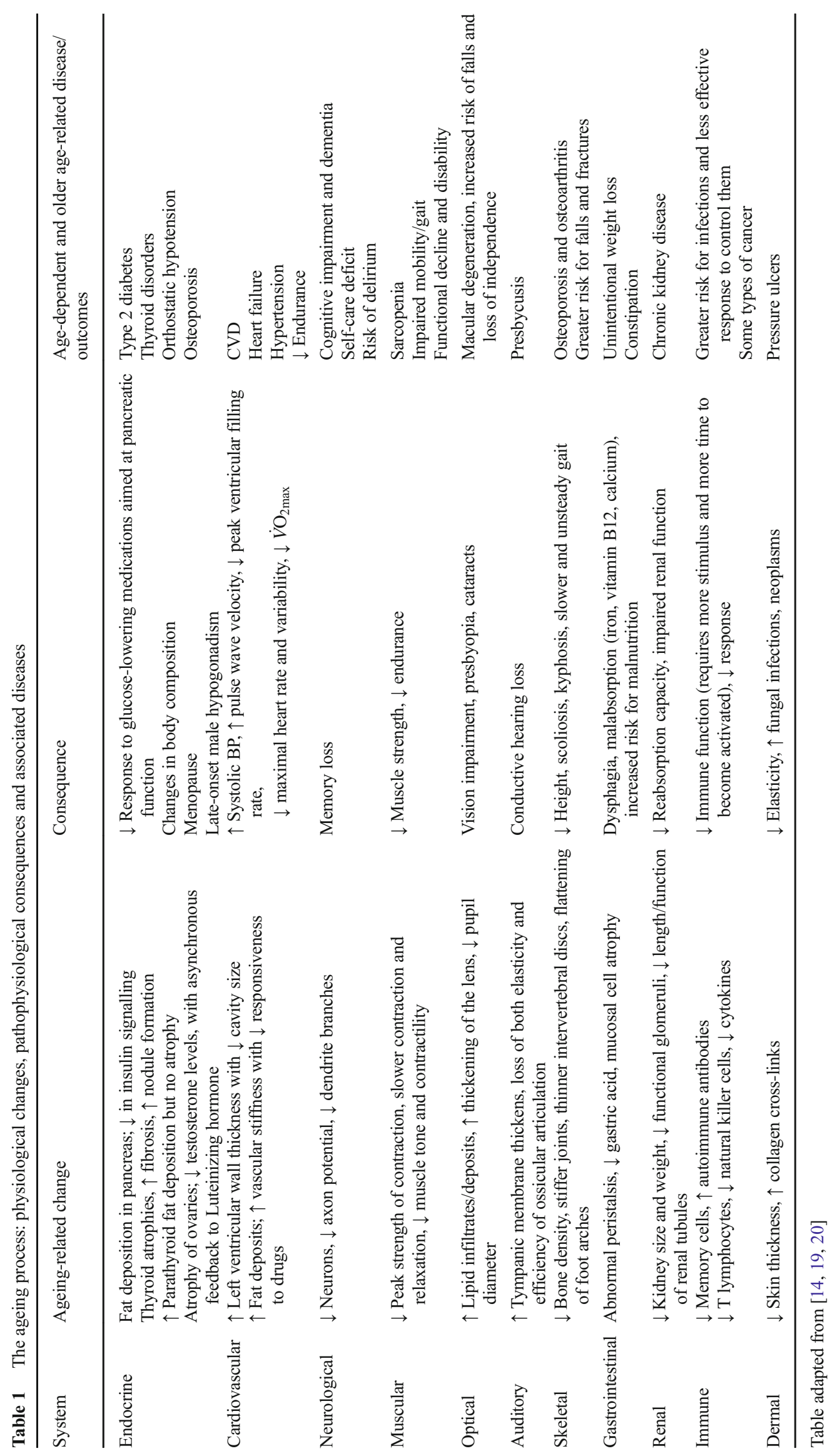




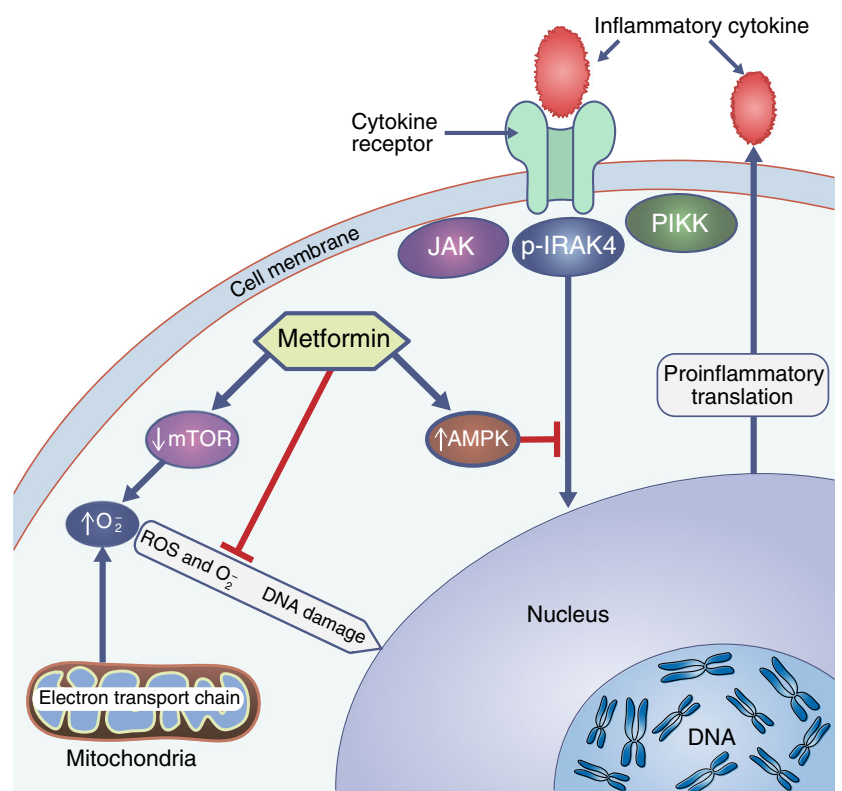

Fig. 1 Anti-ageing mechanisms of metformin. Metformin impacts on mechanisms of ageing, preventing DNA damage and inflammation; it activates the AMP-activated protein kinase (AMPK) signalling pathway, blocking inflammatory-cytokine mediated DNA translation. It also prevents DNA damage from excess production of superoxide by directly decreasing ROS synthesis via reverse electron flux, and by inhibiting mTOR signalling pathways that result in superoxide production. IRAK4, IL-1 receptor-associated kinase 4; JAK, Janus kinase signalling pathway; $\mathrm{O}_{2}^{-}$, superoxide; PIKK, phosphatidylinositol 3-kinase

frailty and by $48 \%$ among those at high cardiovascular risk. Another recent large double-blind randomised, placebocontrolled trial evaluated the cardiometabolic effects of metformin in adults with type 1 diabetes (for $\geq 5$ years) and high CVD risk [40]. Participants had an average age of $55.2 \pm 8.5$ years and $88 \%$ had overweight or obesity. After 3 years, there was no difference in the primary outcome of carotid artery intima-media thickness (a surrogate marker of CVD). Still, there were reductions in body weight, LDL-cholesterol, and also in atherosclerosis progression, based on maximal carotid artery intima-media thickness analysis.

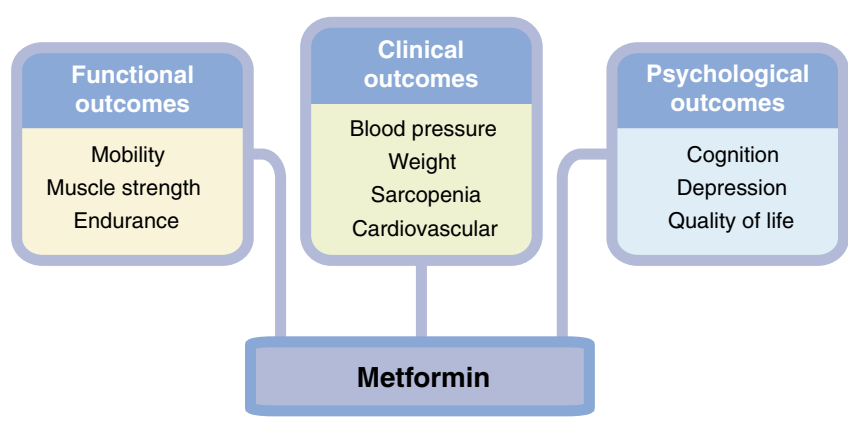

Fig. 2 Potential clinical targets for metformin, beyond glycaemic control. In the ageing individuals, metformin may provide many benefits other than glycaemic control. These benefits may improve physical function (e.g. mobility, muscle strength and endurance), clinical outcomes (e.g. blood pressure, weight and cardiovascular health) and psychological health (e.g. cognition, depression and quality of life)
These findings highlight the potential of metformin for decreasing CVD risk.

\section{Weight loss}

Several studies have shown a small but beneficial level of weight loss with metformin therapy in individuals without diabetes [41], at risk [42], or with type 2 diabetes [43]. Metformin is not approved as an anti-obesity medication, but practitioners often incorporate off-label use for individuals with obesity at high risk for diabetes.

\section{Inflammation, endothelial function and angiogenesis}

Furthermore, metformin mildly reduces levels of highsensitivity C-reactive protein [44], and improves endothelial function $[45,46]$. While this may be partially related to weight loss, the additional impact of metformin on inflammation, endothelial function and angiogenesis, enhances the benefits of this drug against the ageing process. Notably, a pilot placebo-controlled study of women without diabetes showed that, besides improving variables of vascular function, metformin also improved measures taken during an exercise tolerance test: maximal ST-segment depression, Duke score and chest-pain incidence [47]. These findings provide further evidence that metformin may reduce CVD, supporting its use as an additional therapy to reduce cardiovascular risk factors [48] and complications, including death [49, 50]. Importantly, however, since this effect has been most widely reported in individuals with diabetes, further research is required to fully establish the impact of metformin on CVD risk in those without diabetes [41].

\section{Psychological health}

Depression Regarding the psychological health, in a placebocontrolled Chinese study in participants with type 2 diabetes and mild to moderate depression, metformin improved depressive symptoms [51], possibly because of better glycaemic control. Considering the established relationship and high prevalence of depression in older individuals with or without diabetes, this outcome is highly relevant.

Cognitive function There is also evidence that metformin alters cognition. Observational studies show reductions in mild cognitive impairment (MCI) [52] and dementia [53, 54] among participants with diabetes taking metformin when compared with no medication or other glucose-lowering agents. For example, a Taiwanese study in individuals aged $\geq 50$ years found that metformin use significantly decreased the risk of dementia 
compared with no medication (HR 0.76 [95\% CI $0.58,0.98]$ ) [51]. In another study, researchers evaluated data from 365 individuals from the Singapore Longitudinal Aging Study, aged $\geq 55$ years; they found that metformin use was associated with lower risk of MCI (OR 0.49 [CI 0.25, 0.95]) [53]. In another study in Taiwan, researchers analysed data from 67,731 individuals using an insurance database and found that dementia risk was lower in those taking metformin compared with other glucoselowering medications [54]. It must be noted that, because of their observational design, and despite adjusting models for confounders, such as age, education, diabetes duration, CVD and other risk factors, the possibility of residual confounding in these studies persists. Nonetheless, while these studies have limitations, a recent pilot clinical trial substantiated their findings by showing that metformin improved cognition in individuals without diabetes [55]. Specifically, 80 individuals, aged 55-90 years, with amnestic MCI and without treated diabetes were randomly assigned to metformin or placebo and followed for 12 months. The participants treated with metformin showed improvements in the selective reminding test, even after adjusting for baseline values for the Alzheimer's Disease Assessment Scale-cognitive subscale (ADAS-cog) score.

On the other hand, concerns were recently raised that metformin may be associated with deleterious effects on cognitive function in older individuals [56]. Researchers reported worsening tau aggregation and abnormal behaviour [57] or impaired spatial memory and visual acuity [58] in mouse models of ageing. Nevertheless, investigators from the DPPOS have just published an analysis of cognitive function, measured 810 years after therapy with metformin [59]. While the results did not support benefit, they did not show negative impact from long-term metformin use.

\section{Physical function}

In regard to the functional medical domain, as mentioned previously, the potential impact of metformin on skeletal muscle may be particularly helpful in sarcopenic obesity. It is yet to be established whether metformin enhances physical function and mobility, or prevents their decline in older adults. However, in an observational study metformin seemed to decrease the likelihood of frailty and other age-related comorbidities [39].

\section{Metformin can be used safely in older adults}

Metformin has been successfully used for long-term treatment in older adults and it is the first-line therapy for type 2 diabetes [60]. It has also been used long-term to prevent diabetes [61]. For individuals who have never previously used metformin, metformin can be safely started at $500 \mathrm{mg}$ per day and slowly titrate (to ensure tolerance) towards the target dose of $1000 \mathrm{mg}$ twice daily, as long as GFR is above $45 \mathrm{ml} \mathrm{min}^{-1}[1.73 \mathrm{~m}]^{-2}$ [62]. Kidney function needs to be monitored in patients and there may be a need to stop metformin in those with signs of kidney disease (for example if there is an acute increase in serum creatinine). After the situation is resolved, metformin can be resumed with caution, as long as GFR remains above $30 \mathrm{ml} \mathrm{min}^{-1}[1.73 \mathrm{~m}]^{-2}[62,63]$, lowering the dose to a maximum of $1000 \mathrm{mg}$ per day if GFR stays above 30 but below $45 \mathrm{ml} \mathrm{min}^{-1}[1.73 \mathrm{~m}]^{-2}$ [62].

Regarding adverse events, there is ongoing debate whether or not metformin is associated with lactic acidosis [64, 65]. Nonetheless, the event frequency is so small that, in most clinical practices, the preventive approach is to temporally place metformin on hold in the setting of hospitalisation, acute kidney injury, use of iodinated-contrast procedures, or in the setting of acute severe illness with hypoxia (all of which increase the risk of lactic acidosis), following which metformin therapy is reimplemented and use is continued [66].

\section{Future developments in metformin research}

We are facing increased healthcare costs in an ageing society, for which interventions to reduce the burden of NCDs and to promote healthy ageing are needed. Lifestyle modifications, including exercise interventions, have several advantages, but are difficult to adhere to and maintain over time [67]. Metformin offers a cost-effective alternative that, besides controlling diabetes or reducing its risk, may improve mood and cognitive and physical functions. Two large metformin clinical trials in individuals without diabetes will soon start to evaluate the benefit of metformin treatment on these outcomes. The Veterans Affairs' Investigation of Metformin in Pre-Diabetes on Atherosclerotic Cardiovascular OuTcomes (VA-IMPACT; ClinicalTrials.gov registration no. NCT02915198) is a placebo-control study in individuals with CVD and intermediate hyperglycaemia, the latter defined as: one measure of glycated $\mathrm{HbA}_{1 \mathrm{c}} 5.7-6.4 \%$ (38.8-46.4 mmol/ mol); two measurements of fasting blood glucose (on separate days) between $5.6 \mathrm{mmol} / \mathrm{l}$ and $6.9 \mathrm{mmol} / \mathrm{l}$; or a 2-h blood glucose level between $7.8 \mathrm{mmol} / 1$ and $11.1 \mathrm{mmol} / \mathrm{l}$ following a 75 g glucose load OGTT; all in the absence of known diabetes or use of a glucose-lowering agent. The primary outcomes include the time to death from any cause, myocardial infarction, stroke, hospitalisation for unstable angina, or symptom-driven coronary revascularisation. The Targeting Ageing with Metformin (TAME) study is another major placebo-controlled trial in older adults without diabetes but at increased risk of functional decline [68]. TAME will evaluate the potential ability of metformin to slow down the development of age-dependent and age-related diseases, including cancer, CVD and dementia. In addition, TAME will include outcomes of physical function and mobility. The former, 
VA-IMPACT, is confirmed to start recruitment in late 2017. The latter, TAME, will undergo the final approval process for 2018. Finally, the Early Prevention of Diabetes Complications in Europe (ePREDICE) is another large multicenter randomised clinical trial, already recruiting participants mostly in Europe, evaluating the impact of metformin (compared with a dipeptidyl peptidase-4 inhibitor) on microvascular complications and cognitive function in individuals with non-diabetic intermediate hyperglycaemia (impaired glucose tolerance, impaired fasting glucose, or both) [69].

\section{Conclusion}

Beyond its impact on glycaemic control and diabetes-related outcomes, metformin has pleotropic effects targeting multiple age-related mechanisms. Cellular and animal studies have found that metformin decreases inflammatory markers, NF- $k B$, ROS and mTOR pathways, thus decreasing DNA damage. In addition, metformin reduces ceramide-dependent damage in myoblasts. Human observational studies have shown that metformin decreases the risk of CVD, cancer, depression and frailty. A pilot study found that metformin may reduce MCI. Upcoming randomised clinical trials will evaluate whether metformin can decrease death from any cause, CVD, stroke, prevent or delay the development of age-dependent diseases, and improve physical and cognitive function. Given its known safety and long-term use in humans, metformin could become a pharmacological intervention against multimorbidity and ageing in individuals with or without diabetes.

Funding WMV is a recipient of grants from the United States Department of Veterans Affairs (Office of Rural Health and Veterans Integrated Service Network 8) and the National Institutes of Health (NCT01794143). AP is a recipient of grants from the United States Department of Veterans Affairs (CSP 2002 VAIMPACT) and the National Institute on Minority Health and Health Disparities. LT is a recipient of grants from the National Heart, Lung, and Blood Institute (SPRINT and SPRINT-ASK) and the United States Department of Veterans Affairs (CSP 594). HF is a recipient of grants from the United States Department of Veterans Affairs (Million Veteran Program) and the National Institutes of Health (NCT01794143).

Duality of interest The authors declare that there is no duality of interest associated with this manuscript.

Contribution statement All authors contributed to the conception, design, literature search and interpretation of data. All authors contributed to the drafting of the manuscript and critically reviewed it. All authors confirmed final approval of the submitted version to be published.

\section{References}

1. World Health Organization (2015) Ageing and health. Fact sheet N404. Available from www.who.int/mediacentre/factsheets/fs404/ en/. Accessed 7 Mar 2017

2. Ford ES, Giles WH, Dietz WH (2002) Prevalence of the metabolic syndrome among US adults: findings from the third National Health and nutrition examination survey. JAMA 287:356-359

3. Bonora $\mathrm{E}$, Kiechl S, Willeit $\mathrm{J}$ et al (2007) Insulin resistance as estimated by homeostatis model assessment predicts incident symptomatic cardiovascular disease in caucasian subjects from the general population: the Bruneck study. Diabetes Care 30:318-324

4. Djioque S, Nwabo Kamdje AH, Vecchio L et al (2013) Insulin resistance and cancer: the role of insulin and IGFs. Endocr Relat Cancer 20:R1-R17

5. Stuart MJ, Baune BT (2012) Depression and type 2 diabetes: inflammatory mechanisms of a psychoneuroendocrine comorbidity. Neurosci Biobehav Rev 36:658-676

6. De Felice FG, Ferreira ST (2014) Inflammation, defective insulin signaling, and mitochondrial dysfunction as common molecular denominators connecting type 2 diabetes to Alzheimer disease. Diabetes 63:2262-2272

7. Espinoza SE, Jung I, Hazuda H (2012) Frailty transitions in the San Antonio longitudinal study of aging. J Am Geriatr Soc 60:652-660

8. Crandall J et al (2006) (DPP research group). The influence of age on the effects of lifestyle modification and metformin in prevention of diabetes. J Gerontol 61:1075-1081

9. Knowler W et al (2014) (DPP research group). HbAlc as a predictor of diabetes and as an outcome in the diabetes prevention Program: a randomized clinical trial. Diabetes Care 38:51-58

10. Losordo DW, Henry TD (2016) New definition of aging?: measuring regenerative capacity in patients. Circ Res 119:774-775

11. Barzilai N, Huffman DM, Muzumdar RH, Bartke A (2012) The critical role of metabolic pathways in aging. Diabetes 61:13151322

12. Goldberg EL, Dixit VD (2015) Drivers of age-related inflammation and strategies for healthspan extension. Immunol Rev 265:63-74

13. Harris RA, Tindale L, Cumming RC (2014) Age-dependent metabolic dysregulation in cancer and Alzheimer's disease. Biogerontology 15:559-577

14. Fedarko N, McNabney MK (2016) Biology. In: Medina-Walpole A, Pacala JT (eds) Geriatrics review syllabus. 9th edn. American Geriatrics Society. Available at https://geriatricscareonline.org/ ProductAbstract/geriatrics-review-syllabus9th-edition/B023/. Accessed 16 Mar 2017

15. Hoeijmakers JHJ (2009) DNA damage, aging, and cancer. N Engl J Med 361:1475-1485

16. Tamariz L, Hare JM (2015) Xanthine oxidase inhibitors in heart failure: where do we go from here? Circulation 131:1741-1744

17. Carney JM, Starke-Reed PE, Oliver CN et al (1991) Reversal of age-related increase in brain protein oxidation, decrease in enzyme activity, and loss in temporal and spatial memory by chronic administration of the spin-trapping compound N-tert-butyl-alphaphenylnitrone. Proc Natl Acad Sci US A 88:3633-3636

18. Milholland B, Suh Y, Vijg J (2017) Mutation and catastrophe in the aging genome. Exp Gerontol 94:34-40

19. Inouye SK, Studenski S, Tinetti ME, Kuchel GA (2007) Geriatric syndromes: clinical, research and policy implications of a core geriatric concept. J Am Geriatr Soc 55:780-791

20. Valencia WM, Florez H (2017) Endocrinology and metabolism. In: Burton J, Lee A, Potter J (eds) Geriatrics for specialists. Springer, Switzerland, pp 269-282

21. Madiraju AK, Erion DM, Rahimi Y et al (2014) Metformin suppresses gluconeogenesis by inhibiting mitochondrial glycerophosphate dehydrogenase. Nature 510:542-546 
22. Tamariz L, Hare JM (2010) Inflammatory cytokines in heart failure: roles in aetiology and utility as biomarkers. Eur Heart J 31:768-770

23. Saisho Y (2015) Metformin and inflammation: its potential beyond glucose-lowering effect. Endocr Metab Immune Disord Drug Targets 15:196-205

24. Mancini SJ, White AD, Bijland S et al (2017) Activation of AMPactivated protein kinase rapidly suppresses multiple proinflammatory pathways in adipocytes including IL-1 receptor-associated kinase-4 phosphorylation. Mol Cell Endocrinol 440:44-56

25. Moiseeva O, Deschenes-Simard X, St-Germain E et al (2013) Metformin inhibits the senescence-associated secretory phenotype by interfering with IKK/NF-kappa B activation. Aging Cell 12: 489-498

26. Batandier C, Guigas B, Detaille D et al (2006) The ROS production induced by a reverse-electron flux at respiratory-chain complex 1 is hampered by metformin. J Bioenerg Biomembr 38:33-42

27. Algire C, Moiseeva O, Deschenes-Simard X et al (2012) Metformin reduces endogenous reactive oxygen species and associated DNA damage. Cancer Prev Res 5:536-543

28. Halicka HD, Zhao H, Li J et al (2012) Potential anti-aging agents suppress the level of constitutive mTOR- and DNA damage-signaling. Aging 4:952-965

29. Jadhav KS, Dungan CM, Williamson DL (2013) Metformin limits ceramide-induced senescence in $\mathrm{C} 2 \mathrm{C} 12$ myoblasts. Mech Ageing Dev 134:548-559

30. Anisimov VN, Berstein LM, Egormin PA et al (2008) Metformin slows down aging and extends lifespan of female SHR mice. Cell Cycle 7:2769-2773

31. Cabreiro F, Au C, Leung KY et al (2013) Metformin retards aging in $C$. elegans by altering microbial folate and methionine metabolism. Cell 153:228-239

32. De Haes W, Frooninckx L, Van Assche R et al (2014) Metformin promotes lifespan through mitohormesis via the peroxiredoxin PRDX-2. Proc Natl Acad Sci U S A 111:E2501-E2509

33. Takahashi N, Shibata R, Ouchi N, Sugimoto M, Murohara T, Komori K (2015) Metformin stimulates ischemia-induced revascularization through an eNOS dependent pathway in the ischemic hindlimb mice model. J Vasc Surg 61:489-496

34. Meng X, Chu G, Yang Z et al (2016) Metformin protects neurons against oxygen-glucose deprivation/reoxygenation -induced injury by down-regulating MAD2B. Cell Physiol Biochem 40:477-485

35. E1-Mir MY, Detaille D, R-Villanueva G et al (2008) Neuroprotective role of antidiabetic drug metformin against apoptotic cell death in primary cortical neurons. J Mol Neurosci 34: 77-87

36. Kumar A, Al-Sammarraie N, DiPette DJ, Singh US (2014) Metformin impairs rho GTPase signaling to induce apoptosis in neuroblastoma cells and inhibits growth of tumors in the xenograft mouse model of neuroblastoma. Oncotarget 5:11709-11722

37. Gupta A, Bisht B, Dey CS (2011) Peripheral insulin-sensitizer drug metformin ameliorates neuronal insulin resistance and Alzheimer'slike changes. Neuropharmacology 60:910-920

38. Johnson JA, Simpson SH, Toth EL, Majumdar SR (2005) Reduced cardiovascular morbidity and mortality associated with metformin use in subjects with type 2 diabetes. Diabet Med 22:497-502

39. Wang CP, Lorenzo C, Habib SL, Espinoza SE (2017) Differential effects of metformin on age related comorbidities in older men with type 2 diabetes. J Diabetes Complicat 31:679-686

40. Petrie JR, Chatuverdi N, Ford I et al (2017) Metformin in adults with type 1 diabetes: design and methods of REducing with MetfOrmin vascular adverse lesions (REMOVAL): an international multicentre trial. Diabetes Obes Metab 19:509-516

41. Preiss D, Lloyd SM, Ford I et al (2014) Metformin for non-diabetic patients with coronary heart disease (the CAMERA study): a randomised controlled trial. Lancet Diabetes Endocrinol 2:116-124
42. Goldberg RB, Mather K (2012) Targeting the consequences of the metabolic syndrome in the diabetes prevention Program. Arterioscler Thromb Vasc Biol 32:2077-2090

43. Morgan CL, Jenkins-Jones S, Evans M, Barnett AH, Poole CD, Currie CJ (2012) Weight change in people with type 2 diabetes: secular trends and the impact of alternative antihyperglycaemic drugs. Diabetes Obes Metab 14:424-432

44. Haffner S, Temprosa M, Crandall J et al (2005) Intensive lifestyle intervention or metformin on inflammation and coagulation in participants with impaired glucose tolerance. Diabetes 54:1566-1572

45. Vitale C, Mercuro G, Cornoldi A, Fini M, Volterrani M, Rosano GM (2005) Metformin improves endothelial function in patients with metabolic syndrome. J Intern Med 258:250-256

46. de Aguiar LG, Bahia LR, Villela N et al (2006) Metformin improves endothelial vascular reactivity in first-degree relatives of type 2 diabetic patients with metabolic syndrome and normal glucose tolerance. Diabetes Care 29:1083-1089

47. Jadhav S, Ferrell W, Greer IA, Petrie JR, Cobbe SM, Sattar N (2006) Effects of metformin on microvascular function and exercise tolerance in women with angina and normal coronary arteries: a randomized, double-blind, placebo-controlled study. J Am Coll Cardiol 48:956-963

48. Whittington HJ, Hall AR, McLaughlin CP, Hausenloy DJ, Yellon DM, Mocanu MM (2013) Chronic metformin associated cardioprotection against infarction: not just a glucose lowering phenomenon. Cardiovasc Drugs Ther 27:5-16

49. UKPDS Study Group (1998) Effect of intensive blood-glucose control with metformin on complications in overweight patients with type 2 diabetes (UKPDS 34). Lancet 352:854-865

50. Kooy A, de Jager J, Lehert P et al (2009) Long-term effects of metformin on metabolism and microvascular and macrovascular disease in patients with type 2 diabetes mellitus. Arch Intern Med 169:616-625

51. Guo M, Mi J, Jiang QM et al (2014) Metformin may produce antidepressant effects through improvement of cognitive function among depressed patients with diabetes mellitus. Clin Exp Pharmacol Physiol 41:650-656

52. Ng TP, Feng L, Yap KB, Lee TS, Tan CH, Winblad B (2014) Longterm metformin usage and cognitive function among older adults with diabetes. J Alzheimers Dis 41:61-68

53. Hsu CC, Wahlqvist ML, Lee MS, Tsai HN (2011) Incidence of dementia is increased in type 2 diabetes and reduced by the use of sulfonylureas and metformin. J Alzheimers Dis 24:485-493

54. Cheng C, Lin CH, Tsai YW, Tsai CJ, Chou PH, Lan TH (2014) Type 2 diabetes and antidiabetic medications in relation to dementia diagnosis. J Gerontol A Biol Sci Med Sci 69:1299-1305

55. Luchsinger JA, Perez T, Chang $\mathrm{H}$ et al (2016) Metformin in amnestic mild cognitive impairment: results of a pilot randomized placebo controlled clinical trial. J Alzheimers Dis 51:501-514

56. Moreira PI (2014) Metformin in the diabetic brain: friend or foe? Ann Transl Med 2:54

57. Barini E, Antico O, Zhao Y et al (2016) Metformin promotes tau aggregation and exacerbates abnormal behaviour in a mouse model of taupathy. Mol Neurodegener 11:16

58. Thangthaeng N, Rutledge M, Wong JM, Vann PH, Forster MJ, Sumien N (2017) Metformin impairs spatial memory and visual acuity in old male mice. Aging and Disease 8:17-30

59. Luchsinger JA, Ma Y, Christophi CA et al (2017) Metformin, lifestyle intervention, and cognition in the Diabetes Prevention Program Outcomes Study. Diabetes Care 40:958-965

60. Kirkman SM, Briscoe VJ, Clark N et al (2012) Diabetes in older adults. Diabetes Care 35:2650-2664

61. Knowler WC, Barrett-Connor E, Fowler SE et al (2002) Reduction in the incidence of type 2 diabetes with lifestyle intervention or metformin. NEJM 346:393-403 
62. US Food and Drug Administration. Metformin containing drugs: drug safety communication - revised warnings for certain patients with reduced kidney function. Available from https:/www.fda.gov/Safety/MedWatch/safetyInformation/ SafetyAlertsforHumanMedicalProducts/ucm494829.htm? source 5 govdelivery \&utm_medium 5 email \&utm source5govdelivery. Accessed 24 May 2017

63. European Medicines Agency. Metformin and metformincontaining medicines. Use of metformin to treat diabetes now expanded to patients with moderately reduced kidney function. Available from www.ema.europa.eu/ema/index.jsp?curl=pages/ medicines/human/referrals/Metformin_and_metformincontaining medicines/human_referral_000397.jsp\&mid= WC0b01ac05805c516f. Accessed 24 May 2017

64. Misban RI (2004) The phantom of lactic acidosis due to metformin in patients with diabetes. Diabetes Care 27:1791-1793
65. DeFronzo R, Fleming GA, Chen K, Bicsak TA (2016) Metformin associated lactic acidosis: current perspectives on causes and risk. Metabolism 65:20-29

66. Valencia WM, Florez H (2014) Pharmacological treatment of diabetes in older people. Diabetes Obes Metab 16:11921203

67. Valencia WM, Stoutenberg M, Florez H (2014) Weight loss and physical activity for disease prevention in obese older adults: an important role for lifestyle management. Curr Diab Rep 14:539

68. Newman JC, Milman S, Hashmi SK et al (2016) Strategies and challenges in clinical trials targeting human aging. J Gerontol A Biol Sci Med Sci 74:1424-1434

69. The ePREDICE Consortium (2016) Early Prevention of Diabetes Complications in Europe. Available from www.epredice.eu/en/theproject. Accessed $22 \mathrm{Feb} 2017$ 